\title{
Can pest management and biosecurity benefit from the surveillance and security industries?
}

\author{
S. Hardwick ${ }^{1,4}$, C.M. Ferguson ${ }^{2,4}$, D.J. Wilson ${ }^{3}$ and J. Sik ${ }^{1}$ \\ ${ }^{1}$ AgResearch, Lincoln Research Centre, Private Bag 4749, Christchurch 8140, New Zealand \\ ${ }^{2}$ AgResearch, Invermay Agricultural Centre, Private Bag 50034, Mosgiel 9053, New Zealand \\ ${ }^{3}$ AgResearch, Ruakura Research Centre, Private Bag 3123, Hamilton 3240, New Zealand \\ ${ }^{4}$ Better Border Biosecurity, www.b3nz.org \\ Corresponding author: scott.hardwick@agresearch.co.nz
}

\begin{abstract}
Self-reporting cameras have the potential to revolutionise the trapping networks utilised in pest management and biosecurity. A study was carried out to determine whether commercially available self-reporting camera systems that use $\mathrm{Wi}-\mathrm{Fi}^{\mathrm{TM}}$ and GSM to transmit images to secure websites could be incorporated into trapping networks. Of 45 systems initially examined, one, the RedEye security camera, was laboratory tested. Tests showed that the standard optics package was incapable of distinguishing between clover root weevil (Sitona lepidus) and Argentine stem weevil (Listronotus bonariensis). An upgrade of the camera's optics enabled it be used to successfully monitor porina (Wiseana spp.) flight activity. While this result was encouraging, more research is needed before the technology can be incorporated into trapping networks. In particular, further thought is needed as to the level of image resolution that is required to ensure that the system is relevant to all pest management and biosecurity practitioners.
\end{abstract}

Keywords self-reporting camera, trapping insects.

\section{INTRODUCTION}

Monitoring for the presence of pest species is a key component of pest management and biosecurity programmes. In New Zealand monitoring within such programmes is often achieved by utilising traps baited with an attractant (e.g. Bradley 1998; Hosking et al. 2003; Suckling et al. 2008). Traps need to be visited regularly to check for the presence of the target species. This is time consuming and becomes expensive when networks contain large numbers of traps that are spread over an extensive area. One such network in New Zealand monitors for the presence of fruit flies belonging to the family Tephritidae and consists of ca 7500 traps deployed over ca 3500 sites (Cowley 1990; Stephenson et al. 2003). Automation of trapping networks by transmitting images of the contents of individual traps in combination with image analysis may reduce the costs associated with large trap networks because they only need to be visited for regular maintenance, e.g. to replace lures or to respond to an alert to the presence of a potential target.

Two technologies that could be used to achieve this automation are Wireless internet LAN (Wi-Fi ${ }^{\mathrm{TM}}$ ) and the Global System for Mobile Communications (GSM) (Jain et al. 2008; Fukatsu et al. 2012; Lopez et al. 2012). Prototype 
self-reporting trap systems using technologies such as $\mathrm{Wi}^{-\mathrm{Fi}^{\mathrm{TM}}}$ and GSM to transmit images to trap operators have been developed and field tested (e.g. Jain et al. 2008; Guarnieri et al. 2011; Fukatsu et al. 2012; Lopez et al. 2012). While these studies have validated the concept of self-reporting cameras, with the exception of Fukatsu et al. (2012), they have not produced a commercially viable unit capable of meeting the needs of pest management and biosecurity practitioners. One potential source of off-theshelf Wi-Fi ${ }^{\mathrm{TM}}$ and GSM technologies that could help further develop self-reporting cameras is the security and surveillance industry. Globally this sector has directed significant resources to developing automated smart surveillance systems. These systems have the ability to capture large amounts of data, process it and make decisions on any further action required with little or no human intervention (Langheinrich et al. 2014).

This paper reports on the first stage of a process designed to investigate whether portable selfreporting camera hardware previously developed by the security industry could potentially be incorporated into future trapping networks used by pest management and biosecurity practitioners.

\section{MATERIALS AND METHODS}

\section{Initial assessment of security camera systems}

During December 2009-early January 2010 the specifications of 45 security camera systems were examined to see whether they utilised technologies such as $\mathrm{Wi}-\mathrm{Fi}^{\mathrm{TM}}$ or GSM to transmit images to the end user. After the initial search was undertaken six camera systems were shortlisted and scored against the criteria in Table 1. Further information was requested from five of six companies with camera systems listed in Table 1.

\section{Testing of the RedEye self-reporting camera}

Based on the results of the initial internet search and contact with manufacturers, a RedEye camera unit was obtained from Mi5 Limited (Auckland, New Zealand) and the following tests were conducted at AgResearch, Lincoln, New Zealand, during 14-22 January 2010. Two trap types, a sticky board trap $(230 \mathrm{~mm} \times 140 \mathrm{~mm})$ and a boll weevil cone trap similar to that described in Leggett et al. (1975) were used. In each test, the traps were seeded with two adult Argentine stem weevil Listronotus bonariensis (Kuschel) (Coleoptera: Curculionidae) (approximately $3 \mathrm{~mm}$ long) and two adult clover root weevil Sitona lepidus Gyllenhal (Coleoptera: Curculionidae) (approximately $6 \mathrm{~mm}$ long).

In indoor tests, the RedEye camera was used to capture images of the sticky board and cone traps at distances of 200, 300, 400, 500 and $600 \mathrm{~mm}$. The camera was triggered using the remote control supplied with the RedEye package. The captured images were downloaded and examined to evaluate if the Argentine stem weevil and clover root weevil could be seen and, if so, whether they were identifiable.

To simulate field conditions, the camera was set up outdoors to simultaneously monitor a cone trap and a sticky board trap using a RedEye camera positioned $400 \mathrm{~mm}$ from the trapping surfaces. The camera was programmed to take a picture at $30 \mathrm{~min}$ intervals. After $24 \mathrm{~h}$ the camera was turned off and its internal memory card downloaded. The downloaded images were examined to evaluate if the Argentine stem weevil and clover root weevil could be seen and, if so, whether they were identifiable. The effects of changing light and weather conditions on image quality were also recorded.

\section{BioEye prototype testing}

Based on the results from the tests above, a RedEye camera unit (Mi5 Limited Auckland, New Zealand) was modified by fitting a wide angle lens and 1 Megapixel sensor to overcome the limitations of the standard camera's optics. This unit became known as the BioEye prototype. The BioEye prototype self-reporting camera contained a rechargeable battery pack, internal modem for General Packet Radio Service (GPRS) connection, processor and Secure Digital (SD) memory card. Before being deployed the BioEye prototype was programmed to take a single image at 0900, 2100, 2300 and 0000 hours. When captured, images were stored on an internal SD card and simultaneously sent to a safe repository accessible from the World Wide Web, from which they were then sent to the users via email. After testing the camera at the Lincoln Science 
Centre for $48 \mathrm{~h}$ the unit was deployed at a farm located in the Mamaku district in the North Island of New Zealand to monitor porina adult (Wiseana sp.) flight activity from 4 October 2011 to 1 January 2012. These moths are $20-30 \mathrm{~mm}$ long and can be easily distinguished from other moths by the shape of their wings. The unit was positioned $400 \mathrm{~mm}$ away from a sticky board trap $(230 \mathrm{~mm} \times 140 \mathrm{~mm})$ that had been placed under a 75 watt incandescent light bulb controlled by a timer (Figure 1a). The unit was then turned on using a remote control. The battery pack was replaced every 14-20 days. Porina flight activity was measured by counting the number of moths observed in an image of the sticky board captured at 0000 hours each day. Calibration of these daily image counts was undertaken by recording the number of porina adults on the sticky board when it was replaced every 7 days.

\section{RESULTS}

\section{Initial search}

The initial investigation revealed that cameras could broadly be placed into four groups: trail cameras (6), indoor security systems (14), outdoor security systems (23) and what could be loosely called "gimmicks or toys" (2). Of these, 39 camera systems were not pursued further as they were: too large to be easily used in conjunction with invertebrate traps (31), not weather proof (16), unable to be operated as a standalone unit without significant cabling (e.g. to power source or a phone line) (27) or, most importantly, were not able to internally store and/or transmit images via $\mathrm{WiFi}^{\mathrm{TM}}$ or GSM (34). These failures left a short list of six cameras that had one or more design aspects that could potentially be utilised for selfreporting systems for use in pest management and biosecurity (Table 1). Unsurprisingly no one

Table 1 Specifications of self-reporting security cameras available in 2010 that utilised technologies with the potential to be used in biosecurity and pest management.

\begin{tabular}{|c|c|c|c|c|c|c|}
\hline Parameter & RedEye $^{1}$ & Observer IV ${ }^{2}$ & $\begin{array}{c}\text { Smart } \\
\text { Scouter }^{\mathrm{TM} 3}\end{array}$ & $\begin{array}{c}\text { Mobile } \\
\text { LIVECam }^{4}\end{array}$ & $\begin{array}{c}\text { Cubed } \\
\text { Security } \\
\text { CID }^{5}\end{array}$ & $\underset{\text { GSM }^{6}}{\text { Camit } 1+}$ \\
\hline Weather proof & Yes & Yes & Yes & No & No & No \\
\hline Focal length & $400 \mathrm{~mm}-\infty$ & $400 \mathrm{~mm}-\infty$ & $?-\infty^{5}$ & $400 \mathrm{~mm}-\infty$ & $400 \mathrm{~mm}-$ & $2.5 \mathrm{~mm}-\infty$ \\
\hline Size & $\begin{array}{l}144 \times 84 \times \\
72 \mathrm{~mm}\end{array}$ & $\begin{array}{r}100 \times 70 \times \\
220 \mathrm{~mm}^{7}\end{array}$ & & $\begin{array}{c}100 \times 100 \times \\
100 \mathrm{~mm}\end{array}$ & $?^{5}$ & $\begin{array}{c}48 \times 67 \times \\
102 \mathrm{~mm}\end{array}$ \\
\hline Image Resolution & $750 \mathrm{~K}$ & $750 \mathrm{~K}$ & $1.3 \mathrm{MP}$ & $300 \mathrm{~K}$ & $1.3 \mathrm{MP}$ & $750 \mathrm{~K}$ \\
\hline Motion activated & Yes & Yes & Yes & No & Yes & Yes \\
\hline Scheduling enabled & Yes & Yes & No & No & No & Yes \\
\hline Solar option & Yes & No & No & No & No & No \\
\hline Wi-Fi' ${ }^{\mathrm{TM}}$ Capable & No & No & No & No & No & No \\
\hline Internal GSM modem & Yes & Yes & Yes & Yes & Yes & No \\
\hline Internal data storage & Yes & Yes & Yes & Yes & Yes & Yes \\
\hline Secure web data storage & Yes & No & Yes & No & No & No \\
\hline Battery/Mains powered & Battery & Battery & Battery & Battery & Both & Mains \\
\hline Battery life ${ }^{7}$ & 6 months $^{7}$ & 650 pictures & 4-6 weeks & $3 \mathrm{~h}$ video & Unknown & NA \\
\hline $\begin{array}{l}\text { Potential to operate in } \\
\text { network of traps }\end{array}$ & Yes & $\mathrm{No}^{8}$ & $\mathrm{No}^{9}$ & No & No & Yes \\
\hline Supported in New Zealand & Yes & Yes & No & $\mathrm{No}^{10}$ & $\mathrm{No}^{10}$ & Yes \\
\hline
\end{tabular}

${ }^{1}$ Mi5 Limited Auckland, New Zealand; ${ }^{2}$ Colorado Video Inc., Boulder, Colorado, USA; ${ }^{3}$ ERS Group Inc., Tucker, USA; ${ }^{4}$ Singapore Telecommunications Limited, Singapore; ${ }^{5}$ unable to locate manufacturing details; ${ }^{6}$ JTech Co. Ltd., Taiwan; ${ }^{7}$ Text in bold represents a critical failure; ${ }^{8}$ Camera software lets user set network up on their own hard drive; ${ }^{9}$ While images are stored on a webserver the user has to have a separate account for each camera they own; ${ }^{10}$ No longer available (2014) - either company has stopped supporting the technology or is no longer in business. 
camera met all of the criteria specified. All the short listed cameras were able to take images and store them on an internal memory card. However, of these six cameras only two, the Smart Scouter ${ }^{\mathrm{TM}}$ and RedEye camera systems, transmitted captured images back to a secure server using an internal GSM modem before redistribution of the images to a user's cell phone or email address. Of these two systems, only Mi5 Limited's RedEye security camera had both hardware and software that could be further developed into an integrated trapping and reporting system for processing the data generated by a large number of traps.

\section{RedEye testing}

The camera produced clear images both indoors under low light and outdoors with full sunlight (Figures $1 \mathrm{~b}-\mathrm{d}$ ). Clear images of trapping surfaces were obtained when the camera was positioned 200-400 $\mathrm{mm}$ from the traps (Figures $1 \mathrm{~b}-\mathrm{d}$ ). Argentine stem weevil and clover root weevil that had been seeded onto the traps could be seen as small dark objects (Figure 1b-d), but they could neither be identified to species nor reliably distinguished from windblown detritus, even when the image was magnified (Figure 1e). When the camera was positioned $200 \mathrm{~mm}$ away from the trapping surface the images produced were distorted (i.e. "fish-eyed") and not rectilinear (Figure $1 \mathrm{~b}$ ). In the outdoor test, rain caused water to run down the face of the camera casing and lens, which resulted in blurred and unreadable images (Figure 1f).

\section{BioEye testing}

The prototype BioEye camera was a stable platform that experienced no failures during the testing period. All images recorded were successfully transmitted via GRSM modem to the cellular network. These date stamped images were available to be viewed on a web accessible user account and were automatically sent via email to the user in near real time. The images sent to Mi5 Limited, Auckland, New Zealand, clearly showed the trapping surface, and individual porina were able to be identified and counted when present (Figures $1 \mathrm{~g} \& \mathrm{~h}$ and 2 ). It was unlikely that the camera interfered with the light trap's performance as the trapping surface was completely covered with captured porina during periods of flight activity (Figure 1h). Three peaks of porina flight activity were recorded by the BioEye camera during the monitoring period (Figure 2). The first and largest peak occurred on 2 December 2011 when 42 adult moths were counted in the image of the sticky board (Figure 2). Smaller peaks in porina flight activity occurred on 21 and 27 December 2011 (Figure 2). One interesting observation was that most porina recorded in pictures taken at 0000 hours (Figure 1h) were removed from the trapping surface by birds before the next picture was taken at 0900 hours (Figure 1i). As a result it was not possible to accurately count the number of porina trapped by a sticky board over the 7 days prior to it being replaced. The prototype BioEye camera functioned for up to 14 days when taking four images per day before the battery ran flat.

\section{DISCUSSION}

None of the security cameras examined in this study could immediately be used as a selfreporting camera in conjunction with invertebrate traps in a trapping network. However, the Mi5 RedEye camera and associated prototype BioEye camera that was field tested were stable and reliable electronic platforms that have the potential to be further developed. During all tests the performance of the optics was the main limitation of the RedEye and prototype BioEye cameras. While both captured clear images, it will be difficult to integrate the focal distance of $400 \mathrm{~mm}$ with invertebrate traps commonly used in pest management and biosecurity. This issue may be easily addressed by changing to a more suitable lens. However, developing appropriate specifications for image resolution may be more difficult due to the demands created when using a self-reporting camera system to monitor for the presence of different pest species. In the current study the $740 \mathrm{k}$ image sensor installed in the RedEye self-reporting camera was unable to provide an image that enabled the small-bodied clover root weevil or Argentine stem weevil to be clearly identified. To address this issue a $1 \mathrm{MP}$ sensor was installed in the prototype BioEye camera. In a field test this resulted in the relatively large porina adults being easily identified in captured images. These images allowed the users to more 

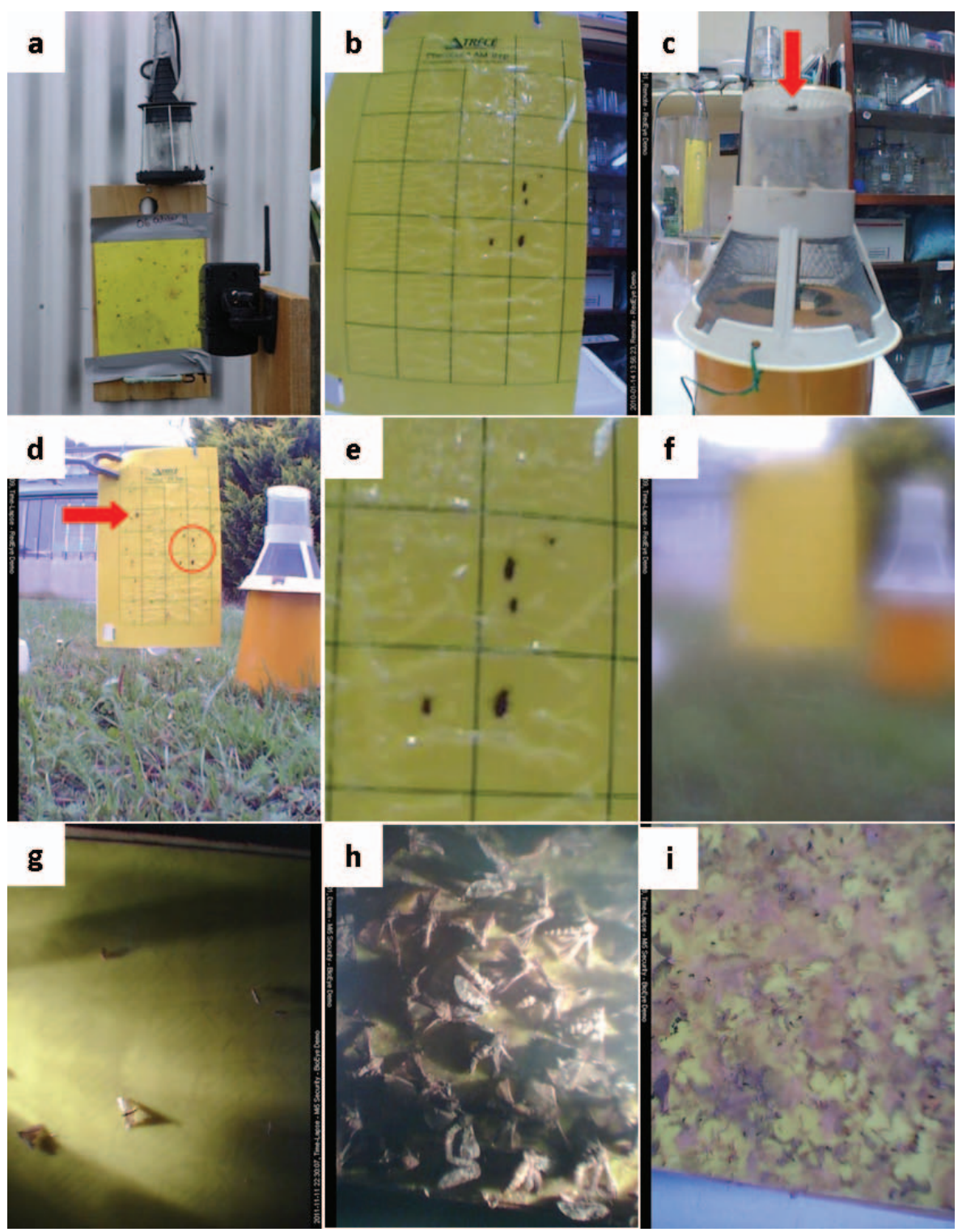

Figure 1 (a) Prototype BioEye camera deployed to monitor light trap in Mamaku; (b) Image of sticky trap taken indoors with RedEye camera positioned $200 \mathrm{~mm}$ from trapping surface; (c) Image of cone trap indoors taken with RedEye camera positioned $200 \mathrm{~mm}$ from trapping surface; adult clover root weevil are indicated with an arrow; (d) Image of sticky cone traps taken out doors with RedEye camera positioned $400 \mathrm{~mm}$ from trapping surface, wind-blown detritus is indicated by an arrow and target weevils are circled; (e) Image of sticky trap taken indoors with RedEye camera positioned $200 \mathrm{~mm}$ from trapping surface magnified 2.5×; (f) Image of traps taken with RedEye camera after rain shower showing smearing of image caused by moisture on camera casing; (g) Image taken by prototype BioEye camera of trapping surface when no porina were flying; (h) Image taken by prototype BioEye camera of trapping surface during a porina flight; (i) Image taken by BioEye camera the morning after porina flight (birds have remove all porina from the trapping surface). 


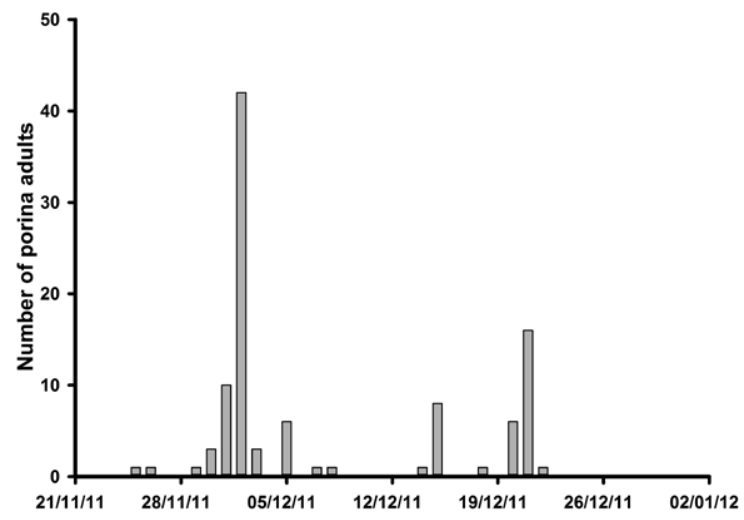

Figure 2 Numbers of porina (Wisena spp) adults observed in images of a sticky board positioned below a light trap located on a farm in Mamaku (images captured at 0000 hours each day).

accurately count the number of porina caught on sticky boards compared to the usual method of physically counting the number of individuals when sticky boards are replaced. It is possible that the current prototype BioEye self-reporting camera could therefore be used to monitor traps baited with target-specific attractants for other Lepidopteran species of a size that is similar to, or larger than, porina. Species fitting this description that are currently or have previously been the target of large-scale trapping networks in New Zealand, include gypsy moth Lymantria dispar (Linnaeus) (Ross 2005); white spotted tussock moth Orgyia thyellina Butler (Hosking et al. 2003); painted apple moth Teia anartoides Walker (Lepidoptera Lymantriidae) (Suckling et al. 2007) and fall webworm Hyphantria cunea (Butler) (Lepidoptera: Arctiidae) (El-Sayed et al. 2005). However, the resolution was still insufficient to enable identification or detection of smaller invertebrates. This poses a significant problem as some of the species that are currently, or potentially could be, monitored in the future are small, cryptic and trapped using non-specific lures, e.g. fruit flies belonging to the family Tephritidae (Cowley 1990; Stephenson et al. 2003) and spotted drosophila Drosophila suzukii (Matsumura) (Diptera: Drosophilidae) (Landolt et al. 2012; Basoalto et al. 2013). It is likely that the prototype BioEye self-reporting camera would need its image sensor upgraded to enable it to capture images of sufficient quality to enable the unit to be used in a wide range of pest management and biosecurity applications.

With any potential self-reporting camera system, thelonger a unit can beleft in the field before it requires maintenance (i.e. battery replacement) the more attractive it will become to a user. In systems based on wireless transmission of image data to a base station, $90 \%$ of power consumption occurs during the download of image slices from the camera and their subsequent transmission (Lopez et al. 2012). A similar situation occurs in the prototype BioEye self-reporting camera (N. Mooyman, Mi5 Limited, Auckland, New Zealand, personal communication). Furthermore as image size increases the amount of energy required to transmit it increases (Lopez et al. 2012). Currently, with a 1 MP sensor installed, the battery life of the prototype BioEye was 14 days. However, in the current test the unit was taking four pictures per day. In a biosecurity or pest management situation it is unlikely that more than one picture of a trapping surface would be needed each day. Reducing the number of pictures taken to this level is likely to stretch the operational period of the camera to ca 6 weeks. However, if the image sensor capability is increased too much then these gains would be largely lost (N. Mooyman, Mi5 Limited, Auckland, New Zealand, personal communication) and an increase in the battery pack size would be required.

In conclusion, this study found that two current off-the-shelf technologies previously developed by the security and surveillance industry have the potential to be incorporated into self-reporting cameras for biosecurity and pest management. However, there needs to be further research undertaken by the science community, together with representatives of the biosecurity, pest management, security and surveillance industries, to develop fit-forpurpose specifications that enable a future self-reporting camera system to meet the needs of end users. In particular, a greater understanding of the requirement, or lack thereof, for greater image quality is needed. Once this issue has been resolved then other issues, such as battery life and casing design, can be addressed. 


\section{ACKNOWLEDGMENTS}

The authors would like to acknowledge the cooperation and assistance of Nick Mooyman and Mi5 Limited, Auckland, New Zealand, in the testing and phase one development of the BioEye camera. The authors would also like to thank Craig Phillips, John Proffitt and Mark McNeill for their early work in developing and demonstrating the concept of self reporting cameras. This study was funded by AgResearch through the Better Border Biosecurity (B3) programme (www.b3nz.org).

\section{REFERENCES}

Basoalto E, Hilton R, Knight A 2013. Factors affecting the efficacy of a vinegar trap for Drosophila suzikii (Diptera; Drosophilidae). Journal of Applied Entomology 137:561-570.

Bradley S, Walker JTS, Wearing CH, Shaw PW, Hodson AJ 1998. The use of pheromone traps for leafroller action thresholds in pipfruit. Proceeding of the 51st New Zealand Plant Protection Conference: 173-78.

Cowley JM 1990. A new system of fruit fly surveillance trapping in New Zealand. New Zealand Entomologist 13: 81-84.

El-Sayed AM, Gibb AR, Suckling DM 2005. Chemistry of the sex pheromone gland of fall webworm, Hyphantria cunea discovered in New Zealand. New Zealand Plant Protection 58: 31-36.

Fukatsu T, Watanabe T, Haoming H, Yoichi H, Hirafuji M 2012. Field monitoring support system for the occurrence of Leptocorisa chinensis Dallas (Hemptera: Alydidae) using synthetic attractants, field servers and image analysis. Computers and Electronics in Agriculture 80: 8-16.

Guarnieri A, Maini S, Molari G, Rondelli V 2011. Automatic trap for moth detection in integrated pest management. Bulletin of Insectology 64: 247-251.

Hosking G, Clearwater J, Handiside J, Kay M, Ray J, Simmons N2003. Tussock moth eradication - a success story from New Zealand. International Journal of Pest Management 49(1): 17-24.

Jain JA, Tseng CL, Lu FM, Yang EC, Wu ZS, Chen CP, Lin SH, Lin KC, Liao CS 2008. A GSMbased remote wireless automatic monitoring system for field information: A case study for the ecological monitoring of the oriental fruit fly Bactrocera dorsalis (Hendel). Journal of Computers and Electronics in Agriculture 62: 243-259.

Landolt PJ, Adams T, Rogg H 2012. Trapping spotted wing drosophila, Drosophila suzukii (Matsumura) (Diptera: Drosophilidae) with combinations of vinegar and wine, and acetic acid and ethanol. Journal of Applied Entomology 136: 148-154.

Langheinrich M, Finn R, Wright D, Coroama V 2014. Quo vadis smart surveillance? How smart technologies combine and challenge democratic oversight. In: Gutwirth S, Leenes $\mathrm{R}$, de Hert $\mathrm{P}$ ed. Reloading data protection: Multidisciplinary insights and contemporary challenges. Springer Science+Business Media, Dordrecht, Netherlands. Pp. 151-182.

Leggett JE, Cross WH, Mitchell HC, Johnson WL, McGovern WL 1975. Improved traps for capturing boll weevils. Journal of the Georgia Entomological Society 10: 52-61.

Lopez O, Rach MM, Migallon H, Malumbres MP, Bonastre A, Serrano JJ 2012. Monitoring pest insect traps by means of low-power image sensor technologies. Sensors 12: 15801-15819.

Ross MG 2005. Response to a gypsy moth incursion within New Zealand. Ministry of Agriculture and Forestry, Wellington, New Zealand. http://www.biosecurity.govt.nz/ files/pests/gypsy-moth/residents/responsegm-incursion.pdf (accessed May 2014).

Stephenson BP, Gill GSC, Randall JL, Wilson JA 2003. Biosecurity approaches to surveillance and response for new plant pest species. New Zealand Plant Protection 56: 5-9.

Suckling DM, Barrington AM, Chhagan A, Stephens AEA, Burnip GM, Charles JG, Wee S L 2007. Eradication of the Australian painted apple moth Teia anartoides in New Zealand: trapping, inherited sterility and male competitiveness. In: Vreysen MJB, Robinson AS, Hendricks J ed. Area-wide Control of Insect Pests. International Atomic Energy Agency, Vienna, Austria. Pp. 603-615.

Suckling DM, Jang EB, Holder P, Carvalho L, Stephens EA 2008. Evaluation of lure dispensers for fruit fly surveillance in New Zealand. Pest Management Science 64: 848-856. 